\title{
O LIVRO DIDÁTICO COMO INSTRUMENTO PEDAGÓGICO PARA O ENSINO DE UM MODELO DE CLASSIFICAÇÃO DO ESPORTE NA EDUCAÇÃO FÍSICA ESCOLAR
}

\author{
EL LIBRO DIDÁCTICO COMO INSTRUMENTO PEDAGÓGICO PARA LA \\ ENSEÑANZA DE UN MODELO DE CLASIFICACIÓN DEL DEPORTE EN LA \\ EDUCACIÓN FISICA ESCOLAR
}

TEXTBOOKS AS EDUCATIONAL TOOLS FOR TEACHING A SPORT
CLASSIFICATION MODEL IN SCHOOL PHYSICAL EDUCATION

André Luís Ruggiero Barroso*, Suraya Cristina Darido**

Palavras-chave

Ensino fundamental.

Esportes.

Classificação.

Materiais de ensino.
Resumo: 0 objetivo deste estudo foi investigar quais modificações foram realizadas pelos professores de Educação Física em relação ao material didático para o ensino do sistema de classificação do esporte no $8^{\circ}$ e $9^{\circ}$ anos do ensino fundamental, de acordo com as suas necessidades, e se essas alterações atendem a outro grupo de professores que atuam no mesmo nível de ensino. 0 método utilizado foi o da pesquisa-ação, elencandose três categorias: compreensão e avaliação do sistema de classificação do esporte, compreensão e avaliação do material didático, implementação do material didático referente ao sistema de classificação do esporte. Na primeira categoria, identificou-se que os fatores positivos foram superiores às possíveis dificuldades; na segunda, foi verificado que os professores se mostraram a favor da utilização de livros pedagógicos; e, na terceira, a importância dos materiais sempre estarem sujeitos a alterações.

Resumen: El objetivo de este estudio fue investigar cuáles fueron las modificaciones realizadas por los profesores de Educación Física en lo que se refiere al material didáctico para la enseñanza del sistema de clasificación del deporte en el octavo y el noveno año de enseñanza, de acuerdo con sus necesidades, y si esos cambios atienden a otro grupo de profesores que trabajan en el mismo nivel de Educación. El método utilizado fue la investigación-acción, enumerando tres categorías: comprensión y evaluación del sistema de clasificación del deporte, comprensión y evaluación del material didáctico e implementación del material didáctico referente al sistema de clasificación del deporte. En la primera se identificó que los factores positivos fueron superiores a las posibles dificultades, en la segunda se encontró que los profesores se mostraron favorables a la utilización de libros pedagógicos y en la tercera se observó la importancia de que los materiales siempre estén sujetos a alteraciones.

Abstract: This study investigated the changes carried out by Physical Education teachers regarding materials used to teach the sport classification system in the eight and nine years of Middle School, according to their needs, and if those changes are appropriate for another group of teachers who work at the same educational level. Action research was used and three categories were built: comprehension and evaluation of the sport classification system; comprehension and evaluation of teaching materials; and implementation of educational materials related to the sports classification system. In the first category, positive factors were higher than potential difficulties; in the second category, teachers were favorable to using of textbooks; and the third category examined the importance of the materials being always open to changes.
*Faculdade de Jaguariúna. Jaguariúna, SP, Brasil.

E-mail: al.barroso@uol.com.br

** Universidade Estadual Paulista. Rio Claro, SP, Brasil.

E-mail: surayacd@rc.unesp.br

Recebido em: 23-05-2016 Aprovado em: 04-10-2016 (c) (1) () Licence 


\section{INTRODUÇÃOO}

Este estudo tratou de dois elementos, procurando relacioná-los com a Educação Física Escolar: 0 conteúdo esporte e o livro didático. Em relação ao esporte, tradicional elemento da Cultura Corporal de Movimento, lançou-se mão de um modelo de classificação. Alguns autores apresentam propostas para classificação de jogos e de modalidades esportivas (BUNKER; THORPE, 1982; PARLEBAS, 2001; FREIRE; SCAGLIA, 2003; GONZÁLEZ, 2004, 2006).

Em Parlebas (2001) é desenvolvido um estudo alicerçado pela Praxiologia Motriz, tendo como referência a situação motora, entendida como uma série de elementos objetivos e subjetivos que caracterizam uma ação motora de um ou mais indivíduos ao executarem uma tarefa motora, em determinado ambiente. Assim, Parlebas (2001) considera a situação motora como um sistema de interação global, envolvendo o praticante, o ambiente em que é realizada a atividade e a eventual participação de outras pessoas. Dessa forma, entende que a ação do indivíduo é analisada a partir de um contexto e não a execução do movimento de forma isolada.

Referenciado pelo estudo da Praxiologia Motriz, González $(2004,2006)$ apresenta um sistema de classificação do esporte baseado na lógica interna, conceituada como "as características de desempenho exigidas pelas situações motoras criadas pelos diferentes tipos de esportes" (GONZÁLEZ, 2006, p. 90).

Para estabelecer a classificação das modalidades esportivas, González $(2004,2006)$ utiliza como referência os critérios de cooperação, interação com o adversário, ambiente, desempenho motor e objetivos táticos da ação. Inicialmente, a partir da ocorrência ou não de interação entre os oponentes, o autor apresenta a estruturação em dois grupos: esportes em que não há interação entre adversários e esportes em que há interação entre adversários. $\mathrm{A}$ partir do primeiro grupo, utilizando o critério acerca do tipo de desempenho motor comparado para designar o vencedor, são estipuladas três categorias de esporte: precisão, marca, técnico combinatório; enquanto que, com a subdivisão do segundo grupo, tendo o critério referente ao objetivo tático da ação ou a exigência que é colocada aos participantes pela modalidade para conseguir o propósito do confronto esportivo, são determinadas mais quatro categorias de esporte: luta ou combate, rede/quadra dividida ou parede de rebote, campo e taco, invasão ou territorial. Entre essas sete categorias de esporte, as de marca, técnico combinatório, de precisão e de rede/quadra dividida ou parede de rebote apresentam a possibilidade de contemplar modalidades individuais e coletivas; já as de campo e taco e de invasão ou territorial apenas coletivas; enquanto que as de luta ou combate somente individuais (GONZÁLEZ, 2004, 2006).

Salienta-se que esse modelo é utilizado como referência para o tratamento do conteúdo esporte no componente curricular Educação Física na Base Nacional Comum Curricular, documento que deverá ser homologado como Lei Federal e terá o propósito de determinar os direitos de aprendizagem dos alunos na Educação Básica (BRASIL, 2016); além de ter sido utilizado na proposta pedagógica do Segundo Tempo referente ao programa de esporte do país (DARIDO; OLIVEIRA; GONZÁLEZ, 2014; GONZÁLEZ; DARIDO; OLIVEIRA, 2014, OLIVEIRA; DARIDO; GONZÁLEZ, 2014). No Referencial Curricular do Estado do Rio Grande do Sul, foi proposto um material didático para ensinar essa classificação do esporte (RIO GRANDE DO SUL, 2009). 
Quanto ao livro didático, verifica-se que esse instrumento de ensino acompanha a trajetória histórica da maioria dos componentes curriculares, entretanto, no caso da Educação Física, ainda se apresenta de forma tímida. Isso pode ser explicado principalmente pelo fato de essa disciplina tradicionalmente estar direcionada apenas ao ensino de movimentos corporais, ligada ao propósito de aprender a fazer, caracterizando a dimensão procedimental do conteúdo (DARIDO; RANGEL, 2005), assim, não sendo necessário o livro didático.

Somente a partir das tendências pedagógicas renovadoras da Educação Física, no início dos anos de 1980, é que se passa a defender o ensino de questões conceituais no trato dos conteúdos específicos desse componente curricular, culminando na possibilidade de elaboração de livros didáticos, tanto para o professor, como para o aluno, conforme se pode constatar em determinadas propostas curriculares (SÃO PAULO, 2008; PARANÁ, 2008; RIO GRANDE DO SUL, 2009).

Ressalta-se que o livro didático na sua história sofre diversas críticas, entre elas, as relacionadas aos critérios de distribuição nas redes de ensino e essencialmente na forma de utilização pelos professores, como também se adverte para o controle que o Estado estabelece sob a prática pedagógica do professor ao determinar o que deva ser ensinado no âmbito escolar (APPLE, 1995; ZABALA, 1998; SACRISTÁN, 2000).

Respeitam-se os apontamentos realizados referentes às críticas ao livro didático, mas se torna necessário refletir em contraposição, pois se tem a ideia de que esse tipo de material deve ser utilizado como um dos instrumentos da prática pedagógica, mas não o único; o professor não deverá se tornar um "escravo" desse material, porém deve utilizá-lo conforme as necessidades do conteúdo a ser desenvolvido (MUNAKATA, 2003"; BITTENCOURT, 2010; DARIDO et al., 2010).

Concorda-se com Bittencourt (2010, p. 545) quando a autora afirma que "o livro é um objeto feito para o professor e é dependente do uso que o professor faz dele". Nesse sentido, Zabala (1998) adverte que o fundamental não está na discussão entre a utilização ou não do material didático, mas, sim, no entendimento referente a quais materiais utilizar e como deverão ser utilizados. Darido et al. (2010) também se posicionam a favor do livro didático, em especial na Educação Física, destacando que ele possa ser um dos materiais possíveis de auxílio ao professor, devendo ser transformado de acordo com as necessidades e realidades educacionais.

É importante advertir que a utilização de livros didáticos nas aulas de Educação Física Escolar não se apresenta como uma opinião comum entre os pesquisadores da área, pois alertam, entre outros aspectos, para a preocupação de tornar o componente curricular meramente teórico e para uma possível dependência pedagógica do professor. Entretanto, verificamse em estudos com professores que atuam na escola fatores favoráveis à utilização desse instrumento na prática pedagógica, como: organização do conteúdo, melhor direcionamento do trabalho pedagógico, inserção de conteúdos conceituais, contribuição aos professores que já apresentam domínio do tema, como também oferecimento de subsídios aos que têm pouco conhecimento no assunto tratado (RODRIGUES; DARIDO, 2011; IMPOLCETTO, 2012; RUFINO, 2012; BARROS, 2014). 
Para o desenvolvimento deste estudo, utilizou-se o material didático - caderno do aluno (LIÇÕES..., 2009a) e caderno do professor (LIÇÕES..., 2009b) - elaborado por professores universitários e professores atuantes no âmbito escolar, construído a partir das orientações estabelecidas no Referencial Curricular do Estado do Rio Grande do Sul (RIO GRANDE DO SUL, 2009).

Nesse material, destinado ao $8^{\circ}$ e 9a anos do ensino fundamental, é apresentada uma unidade didática que tem como principal foco o ensino do sistema de classificação do esporte, também sendo tratada a diferença entre lógica interna e lógica externa e a conceituação de termos do movimento humano, a partir da sugestão de leituras, produção de textos, preenchimento de quadros, vivência e registro de jogos para serem realizados durante 0 tratamento dos temas.

Assim, o objetivo deste estudo foi investigar quais modificações foram realizadas pelos professores de Educação Física em relação ao material didático para o ensino do sistema de classificação do esporte no $8^{\circ}$ e $9^{\circ}$ anos do ensino fundamental, de acordo com as suas necessidades, e se essas alterações atendem a outro grupo de professores que atuam no mesmo nível de ensino.

Destaca-se que, mesmo que o material utilizado na pesquisa não apresente o propósito de servir como um documento que o professor deva seguir na sua íntegra, sem a realização de transformações, mas, sim, como uma ferramenta pedagógica, suscetível às adaptações de cada realidade educacional, a maioria dos professores atuantes no ambiente escolar recebe 0 material sem ter participação da sua elaboração. Portanto, mostra-se significativo verificar as diferentes formas de modificações efetuadas por grupos de professores, entre demais aspectos, quais recortes, inserções e alterações efetuados durante o desenvolvimento das aulas com os seus respectivos alunos, como foi o caso desse trabalho.

\section{PROCEDIMENTOS METODOLÓGICOS}

Para o desenvolvimento desta pesquisa foi realizada uma abordagem de cunho qualitativo, sendo utilizado o método da pesquisa-ação (THIOLLENT, 2003). Para o tratamento dos resultados obtidos nos encontros entre o pesquisador e os professores participantes do estudo foi utilizada a análise de conteúdo (BARDIN, 1991).

Ressalta-se que a escolha do material didático pertencente ao Estado do Rio Grande do Sul se deu devido ao fato de tratar do modelo de classificação do esporte abordado na pesquisa e também por esse tema não se referir a questões regionais, portanto, não havendo nenhum tipo de problema ou prejuízo para o estudo a utilização desse material com professores de outras localidades.

A escolha dos professores para participar do estudo atendeu aos seguintes critérios: estar ministrando aulas para os anos finais do ensino fundamental, especificamente para 8 e/ ou 9ano; ter comprometimento com a área da Educação Física Escolar, ou seja, apresentar um trabalho que procurasse oferecer um tratamento pedagógico aos conteúdos pertencentes ao componente curricular; disponibilidade para participar da pesquisa; estar presente nos encontros com o pesquisador; poder desenvolver as aulas com os seus respectivos alunos; ser 
de localidade próxima à do pesquisador, na região do município de Campinas.

Assim, a pesquisa contou com a participação inicial de quatro professores do sexo masculino e quatro do sexo feminino, tendo as suas respectivas unidades escolares localizadas nos municípios de Campinas, Paulínia, Jaguariúna e Mogi Guaçu, no interior do Estado de São Paulo.

O quadro abaixo apresenta a caracterização dos participantes da pesquisa.

Quadro 1 - Idade, tempo de formação inicial, tempo de atuação na escola, tempo que ministra aulas para $8^{\circ}$ e/ ou 9ำ anos (representados em anos)

\begin{tabular}{|l|c|c|c|c|c|c|c|c|}
\hline PROFESSORES/TEMPO & $\mathbf{1}$ & $\mathbf{2}$ & $\mathbf{3}^{\mathbf{1}}$ & $\mathbf{4}$ & $\mathbf{5}$ & $\mathbf{6}$ & $\mathbf{7}$ & $\mathbf{8}$ \\
\hline Idade & 31 & 42 & 32 & 26 & 32 & 34 & 26 & 30 \\
\hline Formação Inicial & 8 & 8 & 7 & 4 & 9 & 9 & 4 & 9 \\
\hline Aula na Escola & 5 & 6 & 7 & 3 & 6 & 6 & 3 & 4 \\
\hline Aula no 8/9-ano & 5 & 6 & 5 & 3 & 6 & 6 & 2 & 4 \\
\hline
\end{tabular}

Fonte: Elaborado pelos autores da pesquisa.

Conforme verificado no Quadro 1, os dados em relação à caracterização dos participantes mostram que o grupo de professores possui uma formação recente, porém com alguma experiência no ambiente formal de ensino, como também nos anos escolares nos quais é direcionado o material didático do estudo $-8^{\circ}$ e $9^{\circ}$ anos. Essa característica pode ser entendida como positiva, pois, ao relacionar com o estudo de Dessbesell e González (2013), envolvendo o Referencial Curricular do Rio Grande do Sul, os professores com formação mais recente apresentaram uma resposta mais positiva na receptividade do documento, em comparação aos professores que possuíam uma formação mais antiga.

Os professores 1, 2, 5, 6 e 8 atuavam em escolas públicas municipais, enquanto que os professores 4 e 7 , em escolas privadas. Os participantes ficaram à vontade para selecionarem, entre as turmas de $8^{\circ}$ e $9^{\circ}$ anos em que ministravam aulas, as que trabalhariam com o material didático. Adverte-se ainda que o direcionamento para essas turmas ocorreu pelo fato de 0 material didático original contemplar esses níveis de ensino, tendo os professores $5,7 \mathrm{e}$ 8 escolhido uma turma, as professoras 4 e 6 duas turmas, a Professora 1 três turmas e 0 Professor 2 quatro turmas.

$\mathrm{Na}$ pesquisa os professores foram divididos em dois grupos: A (professores 1, 2 e 4) e B (professores 5, 6, 7 e 8), apresentando os seguintes propósitos:

- Grupo A: desenvolvimento das aulas utilizando o material didático original e realização de modificações nele.

- Grupo B: desenvolvimento das aulas com a utilização do material modificado e apontamento de possíveis mudanças no material reelaborado pelo grupo $A$.

A partir dessa estruturação, apresenta-se no Quadro 2 o cronograma desenvolvido durante 0 estudo. 
Quadro 2 - Cronograma da pesquisa

\begin{tabular}{|c|c|c|}
\hline Encontro & Grupo & Assunto \\
\hline 10 & A & Caracterização dos participantes; apresentação da problematização \\
\hline $2^{0}$ & A & $\begin{array}{l}\text { Apresentação e discussão do sistema de classificação; apresentação e } \\
\text { discussão do material didático original }\end{array}$ \\
\hline $3^{0}$ & A & Discussão da utilização do material didático original \\
\hline $4^{0}$ & A & Reestruturação do material didático original \\
\hline $5^{0}$ & $\mathrm{~B}$ & Caracterização dos participantes; apresentação da problematização \\
\hline $6^{0}$ & $\mathrm{~B}$ & $\begin{array}{l}\text { Apresentação e discussão do sistema de classificação; apresentação do } \\
\text { material didático reformulado }\end{array}$ \\
\hline $7^{0}$ & $\mathrm{~B}$ & Discussão da utilização do material didático reformulado \\
\hline $8^{0}$ & $\mathrm{~B}$ & Possíveis alterações no material didático reformulado \\
\hline $9^{0}$ & $A$ e $B$ & Discussão dos resultados \\
\hline $10^{\circ}$ & $A$ e $B$ & Discussão dos resultados \\
\hline
\end{tabular}

Fonte: Elaborado pelos autores da pesquisa

A forma de registro dos encontros ocorreu por meio de aparelho de gravação, sendo posteriormente transcritas as falas na íntegra em documento do Microsoft Office Word, possibilitando assim uma análise dos dados obtidos nas discussões entre o pesquisador e os professores participantes da pesquisa.

Ressalta-se que os participantes do estudo assinaram o Termo de Consentimento Livre e Esclarecido e a pesquisa foi aprovada pelo Comitê de Ética em Pesquisa Envolvendo Seres Humanos, tendo registro CAAE: 27550314.3.0000.5465.

\section{DISCUSSÃO DOS RESULTADOS}

Após a obtenção dos dados, eles foram submetidos à análise crítica de conteúdos (BARDIN, 1991) e, a partir disso, foram elencadas três categorias: a. compreensão e avaliação do sistema de classificação do esporte, b. compreensão e avaliação do material didático, c. implementação do material didático referente ao sistema de classificação do esporte.

\subsection{Compreensão e avaliação do sistema de classificação do esporte}

Inicialmente destaca-se que, entre os participantes da pesquisa, o Professor 2 era o único que apresentava um conhecimento prévio do sistema de classificação do esporte proposto por González $(2004,2006)$ e adotado no estudo.

0 aspecto negativo que se destacou foi 0 fato de ocorrer algumas interpretações equivocadas durante os primeiros contatos com esse modelo de classificação do esporte em relação a existir ou não interferência na ação motora entre adversários, mencionado pelos professores 4, 6 e 8, conforme pode ser verificado no relato: "O negativo que eu vejo é uma confusão, no ciclismo, em corridas de rua. Na natação, eu posso ter interação, tô lá nadando, ele pode me atrapalhar. Eu acho que nas provas abertas, em um espaço aberto, vai ser meio complicado pra eles estarem entendendo" (Professora 4).

Para esclarecimento do apontamento acima mencionado, foi explicado aos participantes que, conforme a proposta de González $(2004,2006)$, a análise da lógica interna tem que ser 
feita observando a essência da modalidade esportiva e não situações específicas, pois podem ocorrer certas avaliações erradas, como, por exemplo, no caso do basquetebol, o jogador ter que apresentar determinada precisão para acertar os arremessos ao longo do jogo, sendo bem característico o lance livre, e, nem por isso, a modalidade se encaixa na categoria de esportes de precisão.

Quanto aos fatores favoráveis, os professores nos dois grupos levantaram pontos como: quebra do ensino tradicional ao tratar do conteúdo esporte, melhor organização e apresentação do conteúdo, diversidade, interesse e curiosidade acerca do tema, aumento no leque de possibilidades de aprendizagem dos alunos, identificação das características presentes em uma mesma categoria, estabelecimento de relações entre modalidades da mesma categoria.

Outros posicionamentos podem ser destacados: "eu acho que com essa classificação ficou mais fácil dos alunos entenderem o objetivo dos esportes [...], a classificação tá muito ligada ao objetivo de cada modalidade" (Professora 6); "eu consigo trabalhar por categoria em minha aula, eu não preciso trabalhar modalidade específica, eu posso pegar uma categoria e abordar de maneira lúdica [...], eu acho que otimiza o trabalho" (Professor 8); "quando a gente faz uma brincadeira de jogos de invasão, por exemplo, pebolim gigante, a gente usa três modalidades: basquete, handebol e futsal, consegue dentro do jogo fazer com que essas três atividades consigam ser jogadas ali" (Professor 7).

Verificou-se que os professores foram estimulados a realizar uma reflexão acerca de como tratam o esporte em suas aulas, levando-os a pensar em uma possível reestruturação quanto ao tratamento deste conteúdo em suas respectivas práticas pedagógicas, conforme defendem autores da área (LAJOLO, 1996; ZABALA, 1998; SACRISTÁN, 2000; BITTENCOURT, 2010; DARIDO et al., 2010; RODRIGUES; DARIDO, 2011).

Isso remete a uma valorização desse sistema de classificação, bem como à importância de verificar a compreensão e a avaliação dos professores durante o seu processo de implementação.

\subsection{Compreensão e avaliação do material didático}

Inicialmente é importante atentar que o grupo A (professores 1, 2 e 4) desenvolveu as aulas com seus respectivos alunos utilizando o material original, enquanto que 0 grupo $B$ (professores 5, 6, 7 e 8) trabalhou com o material modificado pelo primeiro grupo.

Também cabe ressaltar que nenhum dos participantes envolvidos no estudo apresentava experiência no uso de materiais didáticos, entretanto, a maioria utilizava textos, reportagens de jornais escritos, vídeos de jogos, pesquisas na internet para o ensino dos conteúdos conceituais referentes ao conteúdo esporte; ou seja, não usam materiais prontos, mas buscam outros tipos para serem utilizados como didáticos.

O primeiro ponto a se destacar no relato dos professores foi o fato dos dois grupos, ao fazerem uma comparação antes e após o desenvolvimento das aulas, apresentarem uma mudança na avaliação. Antes da utilização do material didático da pesquisa os aspectos negativos mostraram-se em maior número, como o número insuficiente de aulas, o tempo destinado para a execução de atividades de natureza teórica, a leitura de textos longos, a possível dificuldade com o vocabulário e principalmente a insegurança na utilização do material didático. 
O relato abaixo retrata a insegurança demonstrada pelos professores:

Ao mesmo tempo em que o material gera medo, no desenrolar das aulas vai te dando uma segurança, porque você tem no que se apoiar sobre o que você tá ensinando. [...] eu acho que é mais uma ansiedade, eu vou dar conta? Eu vou conseguir passar o conteúdo? Eles vão conseguir entender o conteúdo? Eu acho que essas eram as questões que eu me fazia, o medo era se eu ia conseguir explicar o conteúdo do material, eles entenderem a minha explicação (PROFESSORA 6).

Entretanto, após a utilização do caderno do professor e do aluno, os professores destacaram com maior ênfase os pontos positivos, podendo-se citar: maior segurança no manuseio do material, informações acerca do tema tratado, adequação do conteúdo com o ano escolar, estímulo dos alunos à reflexão e ao debate, podendo ser verificado no posicionamento da Professora 6: "[...] depois foi tranquilo, porque tem um respaldo teórico pros alunos verem, fica até mais fácil você ter o material pra ensinar, do que não ter nada".

Dessa forma foi observado, conforme afirmam Zabala (1998), Munakata (2003) e Bittencourt (2010), que o material didático pode ser um importante instrumento pedagógico do professor, pois, a partir do momento em que os participantes da pesquisa efetivamente utilizaram o material em suas aulas, surgiram aspectos favoráveis que anteriormente não tinham sido previstos.

A Professora 4 também destacou que "pra esse nível de turma, idade, eu acho que o conteúdo foi coerente. Pro professor eu acho que estrutura um pouco e você tem algo que pode ser seguido, mesmo que você tenha que modificar alguma coisa". Observa-se nesse comentário uma atenção voltada tanto ao professor, direcionando o trabalho pedagógico, como para os alunos, entendendo que o tema é compatível à faixa etária.

Galatti, Paes e Darido (2010) destacam que, nos últimos anos, as políticas públicas vêm incentivando a utilização do livro didático no componente curricular Educação Física. Entretanto, deixam um ponto para reflexão, referindo-se à questão dos professores estarem preparados para trabalhar com o livro didático ou se há necessidade de uma capacitação deles para a utilização desse instrumento pedagógico.

Outro ponto que os professores ressaltaram foi quanto à valorização do componente curricular, pois, além dos alunos, também foi demonstrado para os demais integrantes da comunidade escolar, tais como direção, coordenação e professores de outras áreas, que a Educação Física apresenta conhecimentos importantes na formação dos estudantes.

As críticas após a utilização do material, apesar de serem em menor número, também ocorreram, principalmente pelas professoras 1 e 4, que, ao utilizarem o material didático original, mencionaram que a leitura dos textos se mostrou cansativa e assim muitos alunos demonstraram desinteresse, não exatamente pelo tema, mas principalmente devido à parte escrita do material.

Com os dados obtidos nessa categoria de discussão pode-se verificar que os professores participantes do estudo sinalizam positivamente para a utilização de livros didáticos, em particular aprovam o material didático utilizado neste estudo, desde que tenham a liberdade para realizar alterações durante a sua efetiva utilização durante a atuação profissional. 


\subsection{Implementação do material didático referente ao sistema de classificação do esporte}

Nesse tópico de discussão o propósito principal esteve no levantamento das principais alterações sugeridas no material didático pelos professores do grupo A para o ensino do sistema de classificação e como elas foram recebidas pelos componentes do grupo $B$.

Os professores do segundo grupo, após o desenvolvimento das aulas com os seus alunos utilizando o material modificado, tiveram acesso ao material didático original, com 0 propósito de estabelecerem uma comparação entre os dois documentos.

Analisando os posicionamentos dos professores foi significativo identificar a opção de procedimentos diferenciados durante o desenvolvimento das aulas, como: a quantidade de encontros com os alunos; as modificações nas estratégias para a leitura dos textos no caderno do aluno; a inversão, em alguns casos, referente às vivências dos jogos do festival e a apresentação dos critérios para classificação e definição das categorias de esporte; a substituição de alguns jogos sugeridos no material didático original.

Verificou-se, assim, a importância dos professores organizarem o seu planejamento para tratamento da unidade didática, pois, mesmo havendo um material didático como referência, a maioria dos participantes do estudo não se restringiu a seguir rigidamente o que era proposto no documento.

Nesse sentido corroboram os trabalhos de Ladeira et al. (2008) ${ }^{2}$, Rodrigues e Darido (2011), Impolcetto (2012) e Rufino (2012), nos quais os participantes dos respectivos estudos sinalizaram positivamente para a utilização do livro didático nas aulas de Educação Física Escolar, porém, alertaram para a preocupação de não se limitar a utilizar de forma idêntica as propostas sugeridas no material, mas devendo haver a utilização dele com base na realidade encontrada na prática pedagógica de cada professor. Lajolo (1996) também salienta que, por maior qualidade que o livro didático possa oferecer, não significa dizer que o professor não tenha que realizar adaptações nele, pois o seu conteúdo irá proporcionar diferentes leituras para variados professores.

A primeira alteração que chamou a atenção foi a sugestão dada pelos integrantes do grupo A quanto ao número de aulas, pois o material original apresentava um total de seis, sendo sugerido o dobro, doze aulas. Mesmo assim, os professores 6 e 8 utilizaram um número ainda maior, respectivamente dezesseis e quinze aulas. Isso ocorreu por entenderem a necessidade de tratarem com mais tranquilidade os conteúdos do material, incluírem novas atividades e oferecerem um tempo mais apropriado para desenvolvimento das vivências e assimilação dos conceitos abordados.

Outro ponto de destaque foi quanto à alteração na sequência das atividades pelos integrantes do grupo $A$, pois o material original apresentava na sua estruturação a vivência de todos os jogos, denominados então no documento como "festival de jogos", para posteriormente serem apresentados os critérios para classificação, bem como a definição de cada categoria de esporte. Foi sugerido que fossem intercaladas as vivências do festival e as leituras, apontando para a realização dos jogos em que não há interação entre adversários, seguido das leituras

2 LADEIRA, Maria Fernanda Telo et al. O impacto da nova proposta do Estado de São Paulo na opinião dos professores de Educação Física. In: SEMINÁRIO DE METODOLOGIA DE ENSINO DOS PROFESSORES DE EDUCAÇÃO FÍSICA, 2., 2008, São Paulo. Anais... São Paulo: USP, 2008. 
referentes às categorias de esporte: de marca, de precisão e técnico combinatório. No segundo momento, a realização do mesmo procedimento relativo às vivências dos jogos em que há interação entre adversários, seguida das leituras referentes às categorias de esporte: de quadra dividida e parede de rebote, de invasão, de combate e de campo e taco.

Os professores do grupo $\mathrm{B}$, quando perguntados sobre o formato de desenvolvimento, sendo intercaladas a vivência e a leitura, diferentemente do que ocorreu com os participantes do grupo $A$, não estabeleceram um consenso. Enquanto os professores 5 e 6 concordaram com a sugestão, os professores 7 e 8 avaliaram que talvez fosse mais interessante realizar a parte de leitura acerca dos conceitos relativos aos critérios adotados para classificar as modalidades esportivas e às definições das categorias, para depois serem promovidas as vivências; ou seja, defenderam outra forma de apresentação, como no exemplo de justificativa:

Eu acho que fazer uma aula prática, outra aula prática, aí quando a gente chegasse no conteúdo não ia ter significado a atividade de maneira de compreendê-la, de relembrar. Alguns vão até esquecer o que fizeram. Eu acho que quando a gente explica e a gente vai pra prática, eles vão pra prática com a cabeça fervilhando, com o olhar crítico (PROFESSOR 8).

Conforme o posicionamento acima, é defendida a apresentação dos aspectos referentes aos conceitos e às definições, para que o aluno, ao participar da experimentação dos jogos, possa ter uma melhor concentração nos aspectos essenciais manifestados na lógica interna dos diferentes tipos de jogos. Essa questão, conforme Pérez-Gomez (1992) e Pimenta (1998), refere-se a uma concepção tradicional de ensino, havendo a necessidade de inicialmente ser apresentada a teoria para posteriormente utilizá-la na prática.

Pode-se identificar que, no material didático original do estudo, os autores tiveram o propósito de justamente quebrar esse paradigma tradicional, procurando fazer com que os alunos inicialmente experimentassem as práticas sugeridas, para, em seguida, realizar relações destas com as sete categorias de esporte.

Outra modificação sugerida foi realizada pelas professoras 1 e 4 do grupo A, referente à forma de apresentação dos textos e das figuras no caderno do aluno, tratando dos grupos de esportes sem e com interação entre adversários e das categorias de esporte pertencentes a esses dois grupos. A Professora 1 foi contundente na crítica de que a quantidade de leituras estava elevada e as imagens estavam amontoadas, desmotivando o aluno, além de dificultar 0 trato do conteúdo. Para fazer as alterações referentes aos pontos negativos salientados foi sugerida a separação das imagens esportivas, com a identificação de cada esporte, além de uma síntese na definição de cada categoria e da inserção do objetivo em determinados esportes.

Nesse instante foi estabelecido um entrave entre os participantes do grupo A, pois o Professor 2, mesmo admitindo que os seus alunos também demonstraram baixo nível de concentração, desinteresse pela quantidade de leitura e até dificuldade de entendimento de algumas palavras do texto, ainda assim, defendeu a manutenção do formato original, argumentando que, na escola, o aluno deve ser estimulado à leitura, principalmente quando há necessidade do tratamento de determinados conceitos.

Também referente a esse aspecto, quando os professores do grupo A foram questionados acerca de possíveis modificações no material destinado ao professor, todos entenderam que deveria ser mantido, pois seriam necessárias as informações presentes nele 
e a sua forma detalhada de apresentação. Nesse sentido, Darido et al. (2010) e Rodrigues e Darido (2011) advertem para a necessidade do livro do professor apresentar uma estruturação que propicie ao professor informações mais contundentes e aprofundadas a respeito do tema desenvolvido.

Os professores do grupo $\mathrm{B}$, ao serem indagados sobre como avaliariam a melhor forma de estruturação em relação ao material do aluno - mantendo a proposta original ou com as modificações que receberam e com as quais desenvolveram as aulas -, apresentaram uma opinião unânime, indicando que o material modificado é mais adequado para ser tratado 0 tema. Essa constatação pode ser exemplificada em um dos relatos:

Desse jeito que tá o material que nós recebemos ficou fácil de atingir o objetivo. 0 objetivo é isso, é classificar o esporte, ficou muito mais simplificado e eles entendem facilmente desse jeito. Não precisa de todo esse material como era antes pra eles chegarem no objetivo final (PROFESSOR 5).

Os professores desse segundo grupo também destacaram que o material modificado já se apresenta de forma cuidadosa, sendo que o detalhamento apresentado no material original o torna maçante e cansativo para os alunos. Nesse sentido, mesmo sendo importante a participação de professores que estão diretamente ligados à prática pedagógica na elaboração do material original, Arroyo (2001) alerta para a necessidade dos professores serem cada vez mais ouvidos quanto à estruturação e à utilização dos materiais.

Ainda acerca dessa questão, reforça-se que o único que se manteve relutante foi 0 Professor 2, defendendo a ideia de que os alunos devem ser estimulados à leitura. Nesse momento chegou-se a um dilema, pois é determinante o diagnóstico realizado pelos professores acerca da melhor aceitação e do maior envolvimento dos alunos quando se sintetiza o que vai ser tratado; direciona-se ao ponto central do tema, alteram-se rapidamente as atividades e estratégias a respeito do assunto, contudo, fica-se sujeito à superficialidade do conteúdo desenvolvido.

Assim, admite-se que a escola e, por consequência, o professor fiquem diante de um desafio, pois em várias situações é feita a opção de tratamento raso de certos assuntos que mereceriam e necessitariam de um mergulho nas questões fundamentais para que houvesse compreensão dos alunos acerca do conteúdo contemplado. Com isso, mostra-se de forma clara que o professor, para garantir a motivação dos alunos, assume certas escolhas, estabelece determinados caminhos e procedimentos que não estão plenamente de acordo com os seus princípios educacionais.

\section{CONSIDERAÇÕES FINAIS}

Esta pesquisa teve o propósito de interligar dois elementos na prática pedagógica do professor de Educação Física - o sistema de classificação do esporte e o livro didático - com o objetivo de investigar quais modificações foram realizadas pelos professores de Educação Física em relação ao material didático para o ensino do sistema de classificação do esporte no $8^{\circ}$ e $9^{\circ}$ anos do ensino fundamental, de acordo com as suas necessidades, e se essas alterações atendem a outro grupo de professores que atuam no mesmo nível de ensino.

É importante ressaltar que o estudo contou com a participação de sete professores e que eles puderam escolher a(s) turma(s) em que iriam desenvolver as aulas. Também 
se mostra determinante advertir que existiam diferenças na infraestrutura das escolas dos professores, considerando, por exemplo, que cinco deles atuavam em instituições públicas e dois em instituições privadas. Entretanto, a partir da análise dos relatos, destaca-se que os professores conseguiram estabelecer uma relação apropriada entre as características de suas respectivas realidades e os propósitos da pesquisa.

Os participantes estavam divididos em dois grupos, sendo que o primeiro teve a incumbência de desenvolver as aulas com o material original e, a partir disso, sugerir modificações nesse material; enquanto que o segundo utilizou o material modificado com os seus alunos, acatando as sugestões ou levantando possibilidades de novas alterações no material.

Para o tratamento dos dados fez-se a opção pela organização em três categorias, contudo adverte-se que os resultados presentes em cada categoria não se apresentaram de forma independente, pois houve um constante diálogo entre os apontamentos pertencentes às três categorias de análise.

$\mathrm{Na}$ primeira categoria, compreensão e avaliação do sistema de classificação do esporte, os fatores positivos foram superiores às possíveis dificuldades, podendo-se destacar, entre outros aspectos, melhor estruturação e organização do conteúdo e a diversidade de modalidades esportivas contempladas no tratamento pedagógico desse elemento da Cultura Corporal de Movimento.

$\mathrm{Na}$ categoria compreensão e avaliação do material didático, observou-se que os professores participantes da pesquisa se mostraram a favor da utilização de livros didáticos como auxílio na prática pedagógica, em especial o material didático adotado no estudo, porém havendo a liberdade do professor para efetuar substituição de exercícios, inserção de atividades, transformação de tarefas, entre outros fatores que permitem a flexibilidade no trato desse tipo de instrumento pedagógico.

Adverte-se que os autores do material original - professores universitários e professores que atuam na escola - demonstraram a nítida preocupação da adequação do material conforme as diferentes realidades educacionais, para a sua efetiva manipulação no desenvolvimento das aulas. Nesse sentido, os resultados do estudo presente corroboram essa ideia, reforçando a necessidade dos professores serem constantemente consultados acerca da utilização de diferentes materiais didáticos.

$\mathrm{Na}$ última categoria, implementação do material didático referente ao sistema de classificação, pode-se verificar que as alterações não foram em grande quantidade, porém se mostraram contundentes. Observou-se que determinadas alterações efetuadas pelos integrantes do grupo A contemplaram as necessidades de alguns professores do grupo B, entretanto nenhuma delas se apresentou de forma integral. Isso mostra que os materiais sempre estarão sujeitos a modificações, pois é imprescindível que o professor faça a leitura deles e identifique a necessidade de realizar alterações conforme a sua realidade educacional. Desta forma, entende-se que qualquer material será melhor e mais apropriado se professores puderem implementá-lo, avaliá-lo e transformá-lo na prática pedagógica. 


\section{REFERÊNCIAS}

APPLE, Michael Whitman. Cultura e comércio do livro didático. In: APPLE, Michael Whitman.

Trabalho docente e textos: economia política das relações de classe e de gênero em educação.

Porto Alegre: Artes Médicas, 1995. p. 81-105.

ARROYO, Miguel Gonzáles. Experiências de inovação educativa: o currículo na prática da escola. In: MOREIRA, Antônio Flávio Barbosa. Currículo: políticas e práticas. 4. ed. Campinas: Papirus, 2001. p. 131-164.

BARDIN, Laurence. Análise de conteúdo. Lisboa: LDA, 1991.

BARROS, André Minuzzo de. Os conteúdos e a prática pedagógica dos professores de Educação Física: análise do currículo do estado de São Paulo. 2014. 193f. Tese (Doutorado em Desenvolvimento Humano e Tecnologias) - Instituto de Biociências, Universidade Estadual Paulista, Rio Claro, 2014. Disponível em: <http://200.145.6.238/bitstream/handle/11449/108695/000764370. pdf? sequence=1\&isAllowed=y>. Acesso em: 16 set. 2016.

BITTENCOURT, Circe. Livros didáticos de história: práticas e formação docente. In: DALBEN, Ângela; DINIZ, Júlio; LEAL, Leiva; SANTOS, Lucíola (Org.). Coleção didática e prática de ensino. Belo Horizonte: Autêntica, 2010. p. 544-563.

BRASIL. Base nacional comum: documento preliminar. Disponível em: <http://basenacionalcomum. mec.gov.br/\#/site/inicio>. Acesso em: 10 mar. 2016.

BUNKER, David; THORPE, Rod. A model for the teaching of games in secondary schools. Bulletin of Physical Education, v. 18, n. 1, p. 5-8, 1982.

DARIDO, Suraya Cristina et al. Livro didático na Educação Física escolar: considerações iniciais. Motriz, v. 16, n. 2, p. 450-457, abr.jjun. 2010.

DARIDO, Suraya Cristina; RANGEL, Irene Conceição Andrade (Coord.). Educação Física na escola. Rio de Janeiro: Guanabara Koogan, 2005.

DARIDO, Suraya Cristina; OLIVEIRA, Amauri Aparecido Bássoli de; GONZÁLEZ, Fernando Jaime (Org.). Lutas, capoeira e práticas corporais de aventura. Maringá: Eduem, 2014.

DESSBESELL, Giliane; GONZÁLEZ, Fernando Jaime. Referencial Curricular de Educação Física da rede estadual de ensino do Rio Grande do Sul - 2009: sentidos atribuídos pelos professores da região da 36a coordenadoria de educação. In: CONGRESSO BRASILEIRO DE CIÊNCIAS DO ESPORTE (CONBRACE) e CONGRESSO INTERNACIONAL DE CIÊNCIAS DO ESPORTE (CONICE), 18., 2013, Brasília. Anais... Brasília, 2013. p. 1-14. Disponível em: $<$ http://congressos.cbce.org.br/index. php/conbrace2013/5conice/paper/view/5045/2770>. Acesso em: 16 set. 2016.

FREIRE, João Batista; SCAGLIA, Alcides José. Educação como prática corporal. São Paulo: Scipione, 2003.

GALATTI, Larissa Rafaela; PAES, Roberto Rodrigues; DARIDO, Suraya Cristina. Pedagogia do Esporte: livro didático aplicado aos Jogos Esportivos Coletivos. Motriz, v. 16, n. 3, p. 751-761, jul./set. 2010.

GONZÁLEZ, Fernando Jaime. Sistema de classificação de esportes com base nos critérios: cooperação, interação com o adversário, ambiente, desempenho comparado e objetivos táticos da ação. Lecturas, Educación Física y Deportes, v. 71, abr. 2004. Disponível em: < http://www. efdeportes.com/efd71/esportes.htm >. Acesso em: 20 set. 2016. 
GONZÁLEZ, Fernando Jaime. Projeto curricular e educação física: o esporte como conteúdo escolar. In: REZER, Ricardo (Org.). 0 fenômeno esportivo: ensaios crítico-reflexivos. Chapecó: Argos, 2006. p. 69-109.

GONZÁLEZ, Fernando Jaime; DARIDO, Suraya Cristina; OLIVEIRA, Amauri Aparecido Bássoli de (Org.). Práticas corporais e a organização do conhecimento: esportes de marca e com rede divisória ou muro/parede de rebote: badminton, peteca, tênis de campo, tênis de mesa, voleibol, atletismo. Maringá: Eduem, 2014.

IMPOLCETTO, Fernanda Moreto. Livro didático como tecnologia educacional: uma proposta de construção coletiva para a organização curricular do conteúdo voleibol. 2012. 320f. Tese (Doutorado em Desenvolvimento Humano e Tecnologias) - Instituto de Biociências, Universidade Estadual Paulista, Rio Claro, 2012. Disponível em: <http://repositorio.unesp.br/bitstream/handle/11449/106313/ impolcetto $\mathrm{fm} d \mathrm{dr}$ rcla.pdf? sequence=1>. Acesso em: 20 set. 2016.

LAJOLO, Marisa. Livro didático: um (quase) manual de usuário. Em Aberto, v. 16, n. 69, 1996. Disponível em: <http://rbep.inep.gov/index.php/emaberto/article/iewFile/1033/935>. Acesso em: 18 set. 2015.

LIÇÕES do Rio Grande: caderno do aluno, $7^{a}$ e $8^{a}$ séries Ensino Fundamental. 2009a. Disponível em: <http://www.educacao.rs.gov.br/dados/refer curric aluno EF 78.pdf> . Acesso em: 8 nov. 2016.

LIÇÕES do Rio Grande: Linguagens, códigos e suas tecnologias, artes e educação física. 2009b. Caderno do professor: Ensino Fundamental e Médio. Disponível em: < http://www.educacao.rs.gov.br/ dados/refer curric prof vol2.pdf >. Acesso em: 8 nov. 2016.

OLIVEIRA, Amauri Aparecido Bássoli de; DARIDO, Suraya Cristina; GONZÁLEZ, Fernando Jaime (Org.). Práticas corporais e a organização do conhecimento: esportes de invasão: basquetebol, futebol, futsal, handebol, ultimate frisbee. Maringá: Eduem, 2014.

PARANÁ. Secretaria de Estado da Educação. Diretrizes curriculares da educação básica: Educação Física. Curitiba, 2008.

PARLEBAS, Pierre. Juegos, deportes y sociedades: léxico de praxiología motriz. Tradução de Fernando González del Campo Román. Barcelona: Editorial Paidotribo, 2001. p. 50-100.

PÉREZ-GOMEZ, Angel. O pensamento prático do professor: a formação do professor como profissional reflexivo. In: NÓVOA, António. (Org.) Os professores e sua formação. Lisboa: Dom Quixote, 1992. p. 94-114.

PIMENTA, Selma Garrido. A prática (e a teoria) docente ressignificando a didática. In: OLIVEIRA, Maria Rita Neto Sales. Confluências e divergências entre didática e currículo. Campinas: Papirus, 1998. p. 153-176.

RIO GRANDE DO SUL. Secretaria de Estado da Educação. Referencial curricular: lições do Rio Grande, Linguagens, códigos e suas tecnologias. v. 2: Artes e Educação Física. Porto Alegre, 2009.

RODRIGUES, Heitor Andrade; DARIDO, Suraya Cristina. O livro didático na Educação Física escolar: a visão dos professores. Motriz, v. 17, n. 1, p. 48-62, jan./mar. 2011.

RUFINO, Luiz Gustavo Bonatto. "Campo de luta": o processo de construção coletiva de um livro didático na Educação Física no Ensino Médio. 2012. 366f. Dissertação (Mestrado em Desenvolvimento Humano e Tecnologias) - Instituto de Biociências, Universidade Estadual Paulista, Rio Claro, 2012. Disponível em: <http://repositorio.unesp.br/bitstream/handle/11449/99066/rufino lgb me rcla.pdf?sequence=1>. Acesso em: 25 set. 2016. 
SACRISTÁN, José Gimeno. O currículo apresentado aos professores. In: SACRISTÁN, José Gimeno. Currículo: uma reflexão sobre a prática. Porto Alegre: Artmed, 2000. p. 147-163.

SÃO PAULO. Secretaria da Educação do Estado de São Paulo. Proposta curricular Educação Física: ensino fundamental ciclo Il e ensino médio. São Paulo, 2008.

THIOLLENT, Michel. Metodologia da pesquisa-ação. 12. ed. São Paulo: Cortez, 2003.

ZABALA, Antoni. A prática educativa: como ensinar. Porto Alegre: Artmed, 1998. 
